\title{
Appropriateness of a Resuscitation Council (UK) advanced life support course for primary care dentists
}

\author{
P. Coulthard, ${ }^{1}$ C. M. Bridgman, ${ }^{2}$ A. Larkin, ${ }^{3}$ and H. V. Worthington, ${ }^{4}$
}

\begin{abstract}
Objectives To investigate whether a standard Resuscitation Council (UK) ALS course is appropriate for primary care dentists or whether a course should be specifically designed for dentists. Design Opinions canvassed by pre-course expectation and post-course evaluation questionnaires.

Subjects 23 West Pennine primary care dentists providing a general anaesthetic or conscious sedation service who attended an ALS course.

Results Knowledge and skills were rated on a 5-point scale from 1 (not important at all) to 5 (extremely important). Basic airway management $($ mean $=5)$ and anaphylaxis $($ mean $=4.9)$ scored the highest on the 'expectation' questionnaire. Rhythm recognition $(P<0.001)$, defibrillation $(P=0.007)$ and arrest algorithms $(P=0.047)$ were rated as significantly more important after the course than before. Knowledge about rhythm disorder management, cardiac pacing, post-resuscitation care, blood gas interpretation and bereavement were not considered to be so important either before or after the course.

Conclusions Despite rating some aspects as unimportant, all dentists stated that this course had been appropriate. They did not want a specially designed ALS course for dentistry. Taking exactly the same recognised course and assessments as other healthcare professionals and gaining the same certification was felt to be important to this group of dentists.
\end{abstract}

Cortunately, serious medical emergencies in dental practice are ${ }_{\text {not common, }}{ }^{1}$ but that also means that they are all the more likely to be alarming when they do occur. Cardiac arrest is the most acute of all emergencies and the ability to stay calm and successfully manage the situation depends on prior planning and rehearsal for such an event. It has been shown that for those who suffer cardiac arrest outside hospital, survival is increased by $33 \%$ when firstresponse teams defibrillate at the scene within 8 minutes. ${ }^{2}$ Such studies have led to the Department of Health policy that all emergency ambulance crews should include a paramedic trained in advanced life support, as an effective and inexpensive way of significantly improving out-of-hospital cardiac arrest survival. ${ }^{3}$ Indeed

\footnotetext{
${ }^{1 *}$ Lecturer in Oral Surgery, ${ }^{4}$ Reader in Dental Statistics, Manchester University Dental Hospital, Higher Cambridge Street, Manchester M15 6FH; ${ }^{2 *}$ Head of Community Dental Services, Dental Public Health, Tameside General Hospital, Fountain Street, Ashton-under-Lyne OL6 9RW; ${ }^{3 *}$ Resuscitation Training Officer, The Royal Oldham Hospital, Rochdale Road, Oldham OL1 2JH ${ }^{*}$ Resuscitation Council (UK) Advanced Life Support Instructor Correspondence to: Dr Paul Coulthard, Oral and Maxillofacial Surgery, University Dental Hospital of Manchester, Higher Cambridge Street, Manchester, M15 6FH

REFEREED PAPER

Received 10.06.99; accepted 16.09.99

(C) British Dental Journal 2000; 188: 507-512
}

it has been widely shown that it is possible to teach ambulance staff to carry out the extended trained skills of endotracheal intubation, intravenous infusion and ventricular defibrillation. ${ }^{4}$ Even some retail outlets and airlines are providing staff training and equipment for defibrillation.

Some have advocated that advanced life support (ALS) should be widely taught to health professionals. ${ }^{5}$ It has been suggested, for example, that general medical practitioners could enhance their ability to manage cardiac arrests by receiving ALS training and significantly reduce their reliance on the resources of the ambulance service. ${ }^{6}$ Dentists are expected to be proficient in performing basic life support (BLS), ${ }^{7,8}$ which while unlikely to reverse the underlying cause, is an essential 'holding operation' while arranging the immediate transfer of a patient to advanced life support (ALS) services. As the evidence that early defibrillation is so crucial to ventricular tachycardia or fibrillation cardiac arrest outcome, should dentists also be trained in advanced life support? Given the rarity of cardiac arrest in the dental primary care setting, it would seem unnecessary to train, and provide updates to permit skill maintenance, for the whole of the dental profession. However ALS training may be appropriate for those dentists providing treatment under general anaesthesia as it has been reported that patients would expect that the dentist is capable of managing any event which may arise from their treatment. ${ }^{9}$

Recent revision of the General Dental Council's (GDC) Guidance, Maintaining Standards, emphasises that a dentist must have a written protocol and arrangements in place for ALS provision when providing general anaesthesia for dental treatment. ${ }^{8}$ As regards training, the GDC recommend that all those involved in the provision of general anaesthesia must frequently train in simulated emergencies. The Council may well expect that a dentist treating a patient under general anaesthesia would be trained in the provision of ALS although it makes no reference to the level of training that should be acquired.

If some dentists should have the opportunity for ALS training, then what form of course would be appropriate? While 15 years ago, some researchers concluded that the Advanced Cardiac Life Support (ACLS) Training Program in the USA had a positive effect on the subjects' ability, ${ }^{10}$ others recognised that many courses did not teach the knowledge and skills well. ${ }^{11,12}$ Following advice from experts in adult education, experienced ACLS educators, and resuscitation scientists, The American Heart Association produced recommendations in 1992 regarding the educational aspects of courses. ${ }^{13}$ Courses became more standardised and less threatening to candidates. Building on this experience, many courses teaching ALS skills are now available in this country. These 'provider' courses include those dealing with cardiac, trauma and paediatric resuscitation. The Resuscitation Council (UK) has been running ALS courses since 1993. These courses provide consistent teaching 


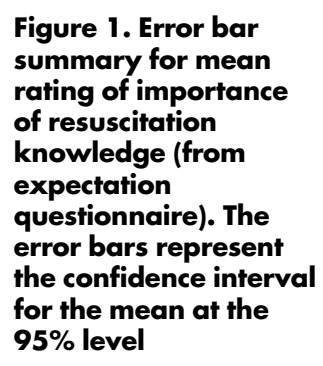

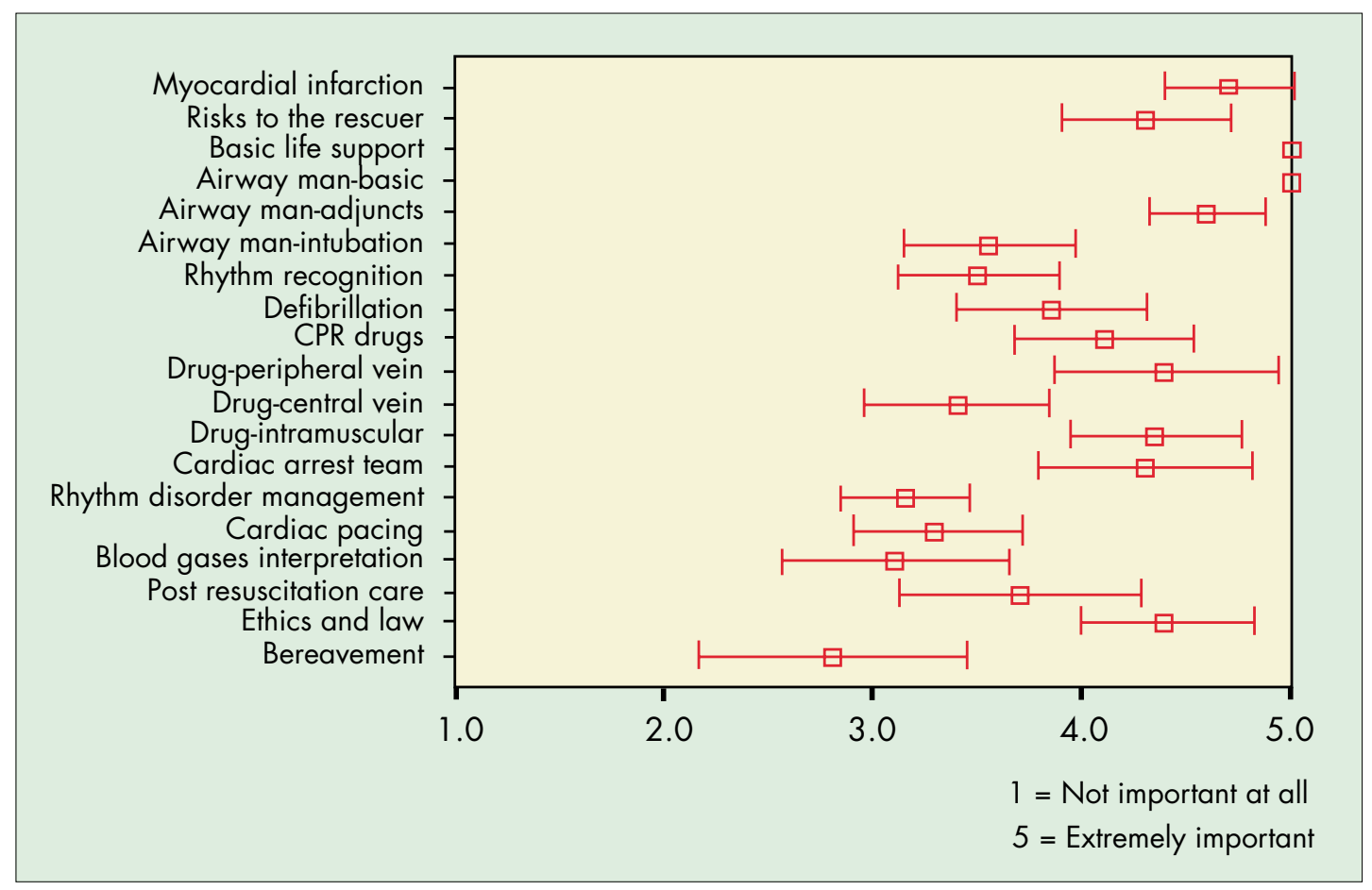

of knowledge and skills and allow practice of the whole cardiac arrest scenario in a realistic manner. ${ }^{14}$ Courses primarily attract health professionals whose jobs include the management of patients in arrest or near-arrest, such as accident and emergency medicine.

Are these the most appropriate courses for primary care dentists or should an 'ALS for dentistry' course be developed? Certainly one of The American Heart Association's recommendations in 1992 was that ACLS course directors should be strongly encouraged to design courses whose content and presentation was best suited to the training, experience, and needs of the course participants. ${ }^{13}$ As the number of applicants for 2 or 3 day ALS courses far exceed the places available, ${ }^{15}$ some have suggested that for this reason alone, an alternative 1-day resuscitation course should be developed as a means of providing tuition that may otherwise be unavailable. ${ }^{16}$

\section{Objectives}

To test the hypothesis that a standard Resuscitation Council (UK) Advanced Life Support course is perceived to be inappropriate for primary care dentists and a more appropriate course should be specifically designed.

\section{Method}

An invitation was extended to all dentists (33) in general dental practice and community dental service in the West Pennine area, who provided a general anaesthetic or conscious sedation service, to attend a 2-day Resuscitation Council (UK) ALS provider course, with the aim of improving their knowledge and skills and undertaking this research. The first 30 were accepted and invited to an introductory evening meeting 6 weeks prior to the course. An ALS course expectations questionnaire was completed by all candidates at the start of this meeting which then proceeded to provide an overview of the course programme, an introduction to ECG interpretation, a role-play demonstration of a whole cardiac arrest scenario (CASDEMO) and issue of the course manuals. Usually the course manuals are mailed to candidates and no pre-course meeting is held.

The 2-day course was held in March 1999. The programme contains lectures, skill stations, workshops and discussions, role-play and scenarios, and assessments. The teaching faculty consists of 16 instructors who act as mentors to candidates in addition to teachers. Instructors have attended an assessed instructor course, which sets out the basic principles of adult learning and all forms of teaching on the provider course are standardised. The course culminates in a cardiac arrest scenario test (CASTEST) which allows knowledge, psychomotor skills and social behaviour to be assessed. ${ }^{17} \mathrm{~A}$ post-course evaluation questionnaire was completed at the end of the course prior to the issue of results and debriefing.

\section{ALS pre-course expectations}

This pre-course questionnaire consisted of two sections.

Section 1 - knowledge

This section gave a list of subjects and asked dentists how important they thought it was for them to have knowledge about each of them. The subjects included all those taught on a standard ASL provider course but also some other subjects such as treatment algorithms for acute asthma and hypoglycaemia, which are not part of the curriculum. Dentists were unaware of the precise ALS course contents at the time of completion of this questionnaire, as they had not received their manuals, and the course announcement flyer did not describe the course contents.

Section 2 - skills

This section gave a list of skills and asked dentists how important they thought it was for them to possess each of them. The list included all those skills taught on a standard ALS course but also some others such as intramuscular injection technique, which is not taught.

\section{ALS course evaluation}

Candidates were asked to rate, on a 5-point scale, all lectures and skill stations according to content, presentation, pre-course knowledge and post-course knowledge which is a normal course requirement. They were also asked to rate the importance of the knowledge and skills taught, and asked if they would have preferred to have a specifically designed course for dentists. General comments and suggestions were also encouraged. Significant difference between the responses of the pre-course expectations and this postcourse evaluation were looked for using the students $t$-test. 


\section{RESEARCH $\underline{\text { medical emergencies }}$}

\section{Results}

Personal details

Twenty dentists completed the pre-course expectation questionnaire and all 23 completed the post-course evaluation questionnaire. Nineteen $(83 \%)$ of the candidates were general dental practitioners and four (17\%) were working in the community dental service. Six (26\%) candidates were female and seventeen (74\%) were male. Four (17\%) were in the $21-30$ year age range, $9(39 \%)$ in the $31-40$ year age range, $8(35 \%)$ in the $41-50$ year age range and 2 $(9 \%)$ in the $51-60$ year age range.

\section{ALS course expectations}

The mean summaries of the answers to the question 'How important do you think it is for you to have knowledge about the following?' are shown on Figures 1 and 2. Candidates were asked to rate the importance on a 5-point scale from 1 (not important at all) to 5 (extremely important). Figure 1 shows summaries for knowledge of subjects other than algorithms for particular types of collapse, which are shown in Figure 2. Knowledge about basic life support and basic airway management scored the highest $($ mean $=5)$ in the general subjects shown in Figure 1, and knowledge of bereavement the lowest score $($ mean $=2.8)$. Knowledge of blood gas interpretation $($ mean $=3.1)$, rhythm disorder management $($ mean $=3.15)$, cardiac pacing $($ mean $=3.3)$, rhythm recognition $($ mean $=3.5)$, endotracheal intubation ( mean $=3.55)$, central venous canulation $($ mean $=3.4)$, post-resuscitation care $($ mean $=3.7)$, defibrillation (mean $=3.8$ ) scored a little higher than bereavement.

For the importance of treatment algorithms, anaphylaxis scored the highest $($ mean $=4.9)$ and cardiac arrest caused by hypothermia $($ mean $=2.65)$ or near drowning $($ mean $=2.65)$, the lowest. Cardiac arrest $($ mean $=4.25)$ did not score as highly as epileptic seizure $($ mean $=4.4)$, acute asthma $($ mean $=4.65)$, angina $($ mean $=4.6)$, hypoglycaemia $($ mean $=4.65)$, or faint $($ mean $=4.7)$. Cardiac arrest because of poisoning $($ mean $=3.5)$ and electrocution $($ mean $=3.3)$ scored lower than cardiac arrest.

The mean summaries of the answers to the question 'How important do you think it is for you to have skill in the following?' are shown in Figure 3. The skills that scored the highest were basic life support $($ mean $=4.95)$ and basic airway management $($ mean $=$
4.95). The skills that scored the lowest were central venous canulation $($ mean $=3.1)$, rhythm recognition $($ mean $=3.5)$ and endotracheal intubation $($ mean $=3.75)$.

\section{ALS course evaluation}

When the course evaluation ratings for importance of subject knowledge were compared with those of the pre-course questionnaire subjects, significant difference was found for several subjects. Candidates rated airway management (paired samples $t$-test, $t=2.21,19$ degress of freedom, $P=0.039)$, rhythm recognition $(P=<0.001)$, defibrillation $(P=0.007)$, arrest algorithms $(P=0.047)$ and cardiac arrest in special circumstances $(P=0.002)$ as being more important after the course. Knowledge of basic life support was rated as significantly less importance after the course $(P=0.042)$.

When the course evaluation ratings for importance of skills were compared with those of the pre-course questionnaire subjects, significant difference was found for several skills. Candidates rated airway management (paired samples $t$-test, $t=4.46,19$ degrees of freedom, $P<0.001)$, rhythm recognition $(P<0.001)$ and defibrillation $(P<0.001)$ as being more important after the course. Knowledge of rhythm disorder management, cardiac pacing, postresuscitation care, blood gas interpretation and bereavement were not significantly different after the course.

The mean score for lecture content was 4.74 (standard deviation $(S D)=0.493)$ and for lecture presentation was $4.73(S D=0.497)$. The mean score for skill station content was $4.96(\mathrm{SD}=0.192)$ and for skill station presentation was $4.96(S D=0.192)$, the highest score being 5 . When pre-course knowledge was compared with post-course knowledge for the lecture subjects there was significant improvement in knowledge for all subjects $(P<0.001)$. When precourse knowledge was compared with post-course knowledge for the skill stations there was significant improvement in knowledge for all stations $(P<0.001)$.

All $23(100 \%)$ candidates stated that they preferred the standard Resuscitation Council (UK) ALS course and did not want a modified ALS course for dentists, even if this were to gain approval of a professional body, such as the Resuscitation Council (UK), Faculty of Dental Surgery or Faculty of General Dental Practitioners of the Royal College of Surgeons. Twenty-one (91\%) preferred to attend a
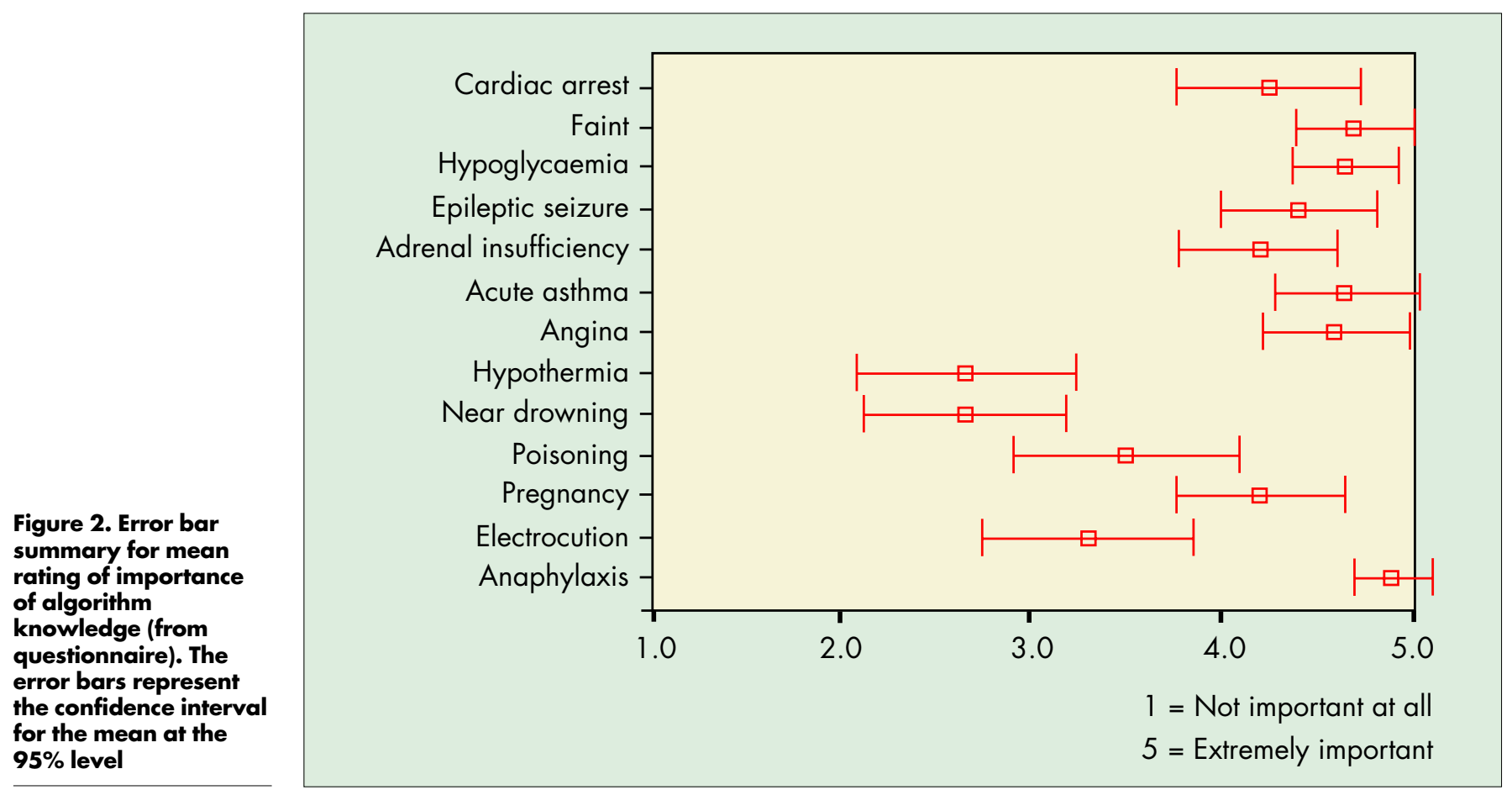


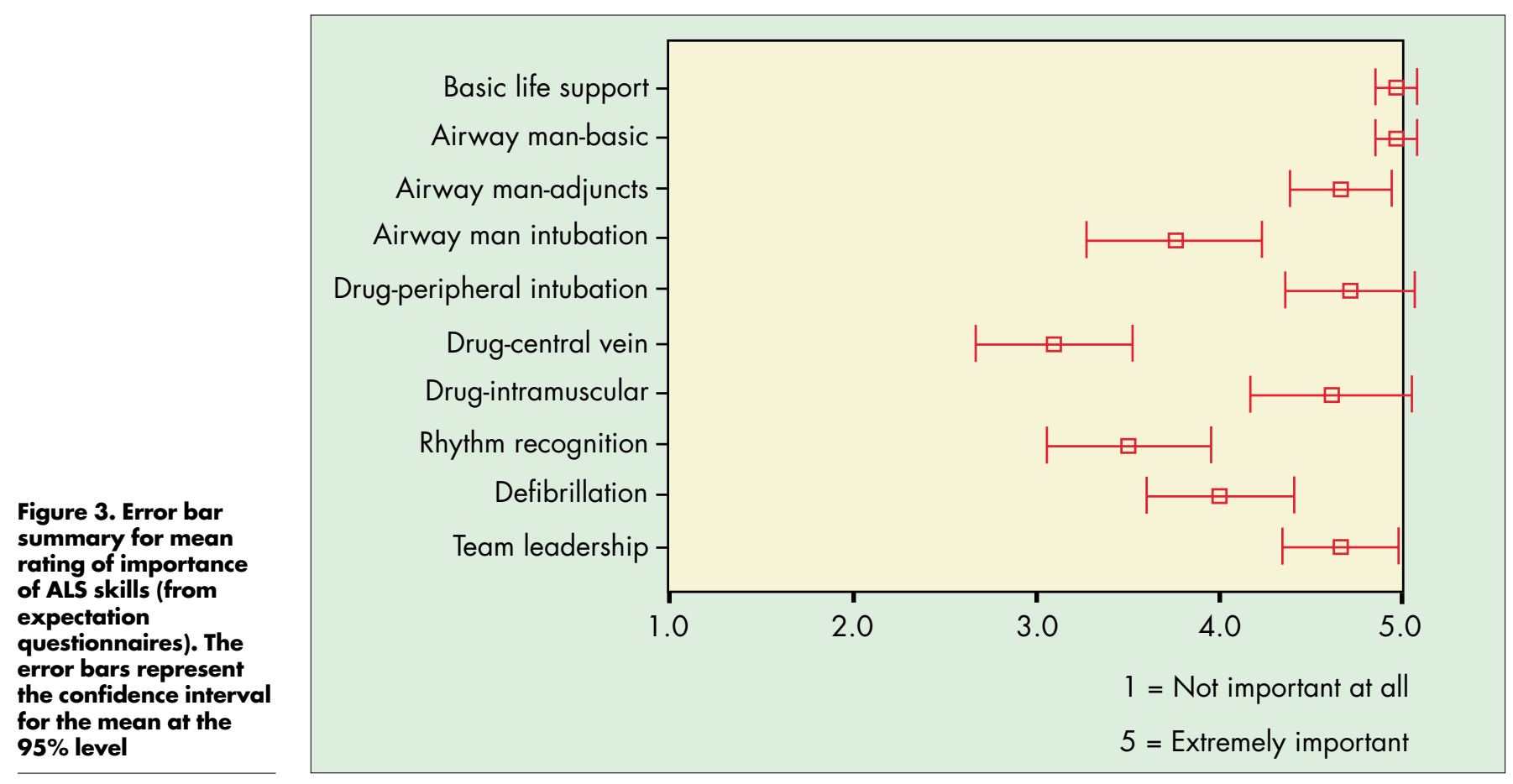

dentist only course rather than the usual mixed professional group course. Twenty-two (96\%) candidates wished to have an additional training module for the management of medical emergencies other than cardiac arrest.

\section{ALS candidate results}

The mean multiple-choice examination paper score was $80.52 \%$. The pass mark is $75 \%$, that is, $90 / 120$ questions, which includes 10 rhythm recognition questions. All candidates passed the basic life support and basic and advanced airway management tests. Four candidates failed the question paper and one candidate failed the CASTEST. Three candidates successfully completed a further attempt at these assessments within a 6-week period after the course and therefore 21 candidates were certified as ALS providers for a 3 -year period.

\section{Discussion}

Before the course, the study dentists were of the opinion that personal knowledge of ALS subjects such as endotracheal intubation, rhythm recognition and defibrillation were not so important. At the conclusion of the course, opinion changed, and these subjects were thought to be significantly more important. With regard to clinical skills, dentists before the course were of the opinion that the most important were, basic life support and basic airway management. Dentists did not rate defibrillation as so highly important, but they did change their opinion after the course, recognising that this skill was significantly more important to them. They also felt that airway management skills including advanced skills and rhythm recognition skills were more important. These changes of opinions suggest that the study dentists were persuaded of the importance of ALS in cardiac arrest management. It must be remembered of course that these results are the opinion of only a small number of dentists who provide treatment under general anaesthesia or conscious sedation.

Knowledge of rhythm disorder management, cardiac pacing, post-resuscitation care, blood gas interpretation and bereavement were also not thought to be so important before the course and opinion did not change about these subjects at the conclusion of the course. Despite this, the candidates did not want the course changed or designed specifically for them as dentists. They wanted no less emphasis on these subjects. Many dentists commented that they preferred to take the same Resuscitation Council course as other healthcare professionals as it had wide recognition. They considered that an ALS course for dentists would not have the same respect. The Resuscitation Council (UK) has in fact already developed courses for particular clinical needs. Healthcare providers caring for paediatric patients in acute care settings may attend a paediatric advanced life support (PALS) provider course administered by the Resuscitation Council and the launch of a neonatal advanced life support provider course is imminent. However, these courses are meeting the educational needs of a variety of healthcare workers involved in care of children or neonates rather than a single professional group of healthcare workers. The evidence of this study to determine whether the course format is appropriate would suggest that there may be no demand for a special dental course. Candidates commented that while some subjects were not so relevant or important for dentists, they found them of interest and were useful in providing the wider context of cardiac arrest management.

Knowledge of basic airway management and basic life support were considered to be extremely important in the pre-course questionnaire and while this opinion did not change for basic airway management at the end of the course, basic life support was found to be significantly less important. Perhaps this was because BLS was well known already and was overshadowed by the advanced life support subject knowledge that was less familiar to the group. Certainly dentists rated BLS skill as more important at the end of the course than before, perhaps the course emphasises the importance of quality BLS in the context of ALS.

Cardiac arrest in special circumstances such as hypothermia or near drowning were not thought to be particularly important before the course and understandably so, as these are not relevant to dental practice. However these were thought to be more important after the course, perhaps because dentists wanted to increase their general professional knowledge that could possibly be of use if encountering such an event away from the workplace.

Central venous canulation scored the lowest of the skills before the course and opinion did not change about the importance after the course. In fact previous course evaluations were such that this skill is no longer taught on ALS course. 


\section{RESEARCH $\underline{\text { medical emergencies }}$}

This was the first ALS provider course organised solely for primary care dentists working in general practice and the community dental service. The majority of dentists stated that they preferred this single profession course, with some commenting that they perceived this to be a more mutually supportive environment. Despite evidence that there has been a low level of BLS and ALS proficiency found among junior doctors ${ }^{15,18-20}$ some study dentists thought that a mixed professional group could be intimidating. This has not been the experience of other groups. In one study, both physicians and nurses believed that a conjoint physician-nurse ALS courses were a good learning experience and an excellent exercise in interprofessional communication and suggested that conjoint courses be maintained, rather than establishing different modules for different professions. ${ }^{21}$ The dentists in this study had no previous experience of a mixed professional candidate course with which to compare this course.

Dentists were asked their opinion of the importance of treatment algorithms for hypoglycaemia, epileptic seizure, angina and faint in the pre-course questionnaire even though these are not part of the course curriculum. Candidates rated all of these as more important than knowledge of the algorithm for cardiac arrest, and this is likely to be because these forms of collapse are more common than cardiac arrest in dental practice. Intramuscular injection technique was also rated highly before the course but this skill is not taught on the ALS course. Dentists did not want the ALS course to include these subjects because again they were very clear that they did not want a special dental course. However, most felt that an additional half-day module to teach and assess the management of medical emergencies other than cardiac arrest would be advantageous. This request for further training by means of formal 'hands-on' training course for dentists in the management of medical emergencies has been reported by others. ${ }^{22}$

Successful completion of the course certifies ALS providers for 3 years, but among ALS providers, retention of knowledge and skills 1 year after courses has been shown to be poor. ${ }^{23,24}$ Some have advocated refresher courses ${ }^{23}$ or six monthly role-play scenarios that reflect the reality of practice based on problems identified in a particular group. ${ }^{24}$ Clearly defined curricula and standardised instructor training have been advocated as important ways to improve retention. ${ }^{12}$ Similar problems with retention 18 months following BLS training in dentistry have been shown. ${ }^{7}$

A recent survey of general dental practitioners has reported that $65 \%$ in England and Wales and $72 \%$ in Scotland of recent graduates, felt that they were either 'not very well' or 'not at all prepared' for dealing with a medical emergency following their undergraduate training. The same study also disturbingly reported that $25 \%$ could not recall receiving any undergraduate training in medical emergencies, although recent graduates were more likely to recall training. Those who recalled undergraduate training were more likely to feel better prepared in the longer term. ${ }^{22}$ While perceptions of confidence may not reflect ability in a real emergency, consideration should be given to improving undergraduate training. A study investigating BLS and ALS training for undergraduate medical students found that there were inconsistencies in resuscitation teaching, with some schools providing formal courses, some teaching specific techniques and others providing no ALS teaching. Most interestingly, only 52\% of UK medical schools considered their present undergraduate training adequate to enable junior house officers to provide an effective resuscitation service. The authors recommended that all aspects of BLS and ALS training for medical undergraduates be improved and standardised throughout the UK. ${ }^{25}$ Similar studies investigating US medical students have drawn the same conclusions. ${ }^{26,27}$ The ALS model could conceivably offer a suitable method of teaching undergraduate dental students.
The aim of this course was to improve ALS skills and knowledge in the primary care dental teams working in the West Pennine area. Dentists' own ratings indicated significant improvement in knowledge and skills following the course indicating that these learning objectives had been met. These personal perceptions were admirably confirmed by the very high success rate.

\section{Conclusions}

Many aspects of the Resuscitation Council (UK) Advanced Life Support provider course were rated as very important to dentists and some others as not important. Despite this, all dentists insisted that this course had been appropriate for them. They did not want a specially designed ALS course for dentistry. Rather than exclude any part and replace with other subject matter, such as management of other medical emergencies, the majority would prefer a standard ALS course with an additional training module for medical emergency management. Taking exactly the same recognised course and assessments as other healthcare professionals and gaining the same certification was felt to be important. Most dentists preferred a 'dentist only' training course even though they did not have experience of a mixed professional course. However it is important to note that these conclusions are drawn from the opinion of a small number of dentists who provide treatment under general anaesthesia or conscious sedation.

The authors thank all the dentists who attended the course and completed the questionnaires so enthusiastically, and all the ALS instructors who taught on the course. This course was funded by the West Pennine Health Authority.

1 Atherton G J, McCaul J A, Williams S A. Medical emergencies in general dental practice in Great Britain. Part 1: their prevalence over a 10-year period. Br Dent J 1999; 186: 72-79.

2 Stiell I G, Wells G A, Field B J et al. Cardiac arrest victims who receive rapid defibrillation have increased survival. J Am Med Assoc 1999; 281: 1175 1181.

3 Nicholl J, Hughes S, Dixon S, Turner J, Yates D. The costs and benefits of paramedic skills in pre-hospital trauma care. Health Technol Assess 1998; 2:1-72.

4 Wright K G. Extended training of ambulance staff in England. Soc Sci Med 1985; 20: 5-712.

5 Atkins J M. Education and evaluation in emergency cardiac care programs (CPR and advanced cardiac life support): state of the art. Circulation 1986; 74: IV18-22.

6 West R J, Penfold N. A questionnaire survey of resuscitation equipment carried by general practitioners and their initial management of ventricular fibrillation. Br J Gen Pract 1997; 47: 37-40.

7 Chate R A C. Evaluation of a dental practice cardiopulmonary resuscitation training scheme. Br Dent J 1996; 181: 416-420.

8 Maintaining standards-guidance to dentists on professional and personal conduct. London: General Dental Council, November 1997, revised November 1998 and May 1999.

9 Peskin R M, Siegelman LI. Emergency cardiac care. Moral, legal and ethical considerations. Dent Clinics of N America 1995; 39: 677-688.

10 Marchette L, Jones S, Bagg A, Cohen A, Palau D, Thaw P. The effect of an advanced cardiac life support course on advanced cardiac life support ability. Heart Lung 1985; 14: 594-598.

11 Kaye W, Mancini M E, Rallis S F, et al. Can better basic and advanced cardiac life support improve outcome from cardiac arrest? Crit Care Med 1985; 13: 916-920.

12 Kaye W, Rallis S F, Mancini M E, Linhares K C et al. The problem of poor retention of cardiopulmonary resuscitation skills may lie with the instructor, not the learner or the curriculum. Resuscitation $1991 \mathrm{Feb} ; 21$ : 67-87.

13 Billi J E, Membrino G E. Education in adult advanced cardiac life support training programs: changing the paradigm. Ann Emerg Med 1993; 22: 475-483.

14 Resuscitation Council (UK). Advanced Life Support Course Provider Manual (3rd Ed) Ed: Advanced Life Support Course Sub-Committee of the Resuscitation Council (UK). London: Resuscitation Council (UK), 1998.

15 Lowenstein S R, Hansbrough J F, Libby L S, Hill D M, Mountain R D, Scoggin C H. Cardiopulmonary resuscitation by medical and surgical house-officers. Lancet 1981; 2: 679-681.

16 Hall D J, Williams M J, Wass A R. Life support courses for all. J Accid Emerg Med 1995; 12: 111-114 
17 Mackway-Jones K, Walker M. Pocket guide to teaching for medical instructors. London: BMJ Books. In collaboration with the Resuscitation Council (UK) 1999.

18 Skinner D V, Camm A J, Miles S. Cardiopulmonary resuscitation skills of pre-registration house officers. Br Med J 1985; 290: 1549-1550.

19 Lum M E. Resuscitation skills of first year postgraduate doctors. NZ Med J 1989; 102: 409-411.

20 Goodwin A P L. Cardiopulmonary resuscitation training revisited. J Roy Soc Med 1992; 85: 452-453.

21 Swanson R W, Ramsden V R. Advanced cardiac life support: a survey of interprofessional attitudes. Heart Lung 1988; 17: 254-255.

22 Atherton G J, McCaul J A and Williams S A. Medical emergencies in general dental practice in Great Britain. Part 3: perceptions of training and competence of GDPs in their management. Br Dent J 1999; 186: 234-237.
23 Jabbour M, Osmond M H, Klassen T P. Life support courses: are they effective? Ann Emerg Med 1996 Dec; 28: 690-698.

24 O'Steen D S, Kee C C, Minick M P. The retention of advanced cardiac life support knowledge among registered nurses. J Nurs Staff Dev 1996; 12: 66-72.

25 Graham C A, Guest K A, Scollon D J. Cardiopulmonary resuscitation. Paper 1: A survey of undergraduate training in UK medical schools. Accid Emerg Med 1994; 11: 162-164.

26 Parrino T A, Parrino N F. The acquisition of practical skills by U.S. medical students. Am J Med Sci 1994; 307: 163-166.

27 Sanders A B, Criss E, Witzke D, Levitt M A. Survey of undergraduate emergency medical education in the United States. Ann Emerg Med 1986; 15: $1-5$.

\section{A change in recording tooth notation}

The BDJ has traditionally adopted the Palmer tooth notation as the first choice for recording individual teeth in papers and articles. This system, very familiar to dentists in the UK, is reproduced below for both adult and deciduous teeth.

$$
\begin{array}{l|l|l|l}
87654321 & 12345678 & \text { EDCBA } & \text { ABCDE } \\
\hline 87654321 & 12345678 & \text { EDCBA } & \text { ABCDE }
\end{array}
$$

In future we are changing the actual way the Palmer system is written because of difficulties of converting the familiar grid format to our website. Instead the position on the grid will be written using the shorthand UR for upper right, UL for upper left, LL for lower left and LR for lower right.

Thus 7 becomes UR7 and $\lceil 5$ is written as LL5. Groups of teeth will be recorded as best we can, so for example 54 will become UR5 and UR4, while 2345 will be written as UL2 to UL5.

Obviously the same will apply to deciduous teeth, for example E will be written as URE.

The FDI notation will still be written in brackets after the Palmer notation, using the familiar FDI notation as described below:

\begin{tabular}{ll|l|l|l|l}
1817161514131211 & 2122232425262728 & for adult teeth
\end{tabular}

\begin{tabular}{l|l|l}
\hline 4847464544434241 & 3132333435363738
\end{tabular}

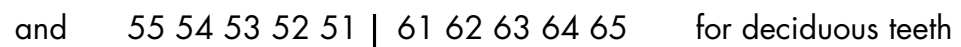

\begin{tabular}{l|l}
5584838281 & 7172737475
\end{tabular}

Thus using both systems, 7] will be written as UR7 (17) and $\sqrt{5}$ will become LL5 (35). 